Results: Preliminary results from the post-training and 3 month follow-up data indicated participants in the training group have reported a significantly more substantial knowledge in disaster mental health, improve self-efficacy in delivering help in times of emergencies, high frequency of actual helping behavior as well as better self-reported psychological well-being when compared with waitlist control group.

Conclusion: This study examines and reports findings of clinical effectiveness of PFA 3 months post training in Chinese emergency responders. Preliminary results provided empirical evidences on the effectiveness of the approach.

Prehosp Disaster Med 2011;26(Suppl. 1):s129-s130

doi:10.1017/S1049023X11004274

\section{(P1-96) Social Context of Natural Disaster}

\section{Maltais}

Human Science, Chicoutimi, Canada

Social context of natural disaster Danielle Maltais, Ph.D., Simon Gauthier, M.Sc. University of Québec in Chicoutimi (UQAC), Social Sciences Department, Social Work Teaching Unit, 555 Boulevard de l'Université, Chicoutimi, Québec, Canada, G7H 2B1, danielle_maltais@uqac.ca During the last few years, several countries in North America as well as in Europe or Asia were exposed to catastrophes that can be described as macrosocial catastrophes since a large number of people were affected. The death of an important number of people during the Katrina hurricane, the 2003 summer heat wave in Europe and the 2004 tsunami in Indonesia unfortunately showed that several countries and communities, even the most developed, are very badly prepared, in the event of a natural disaster, to protect and help its citizens and more specifically vulnerable people such as the old or the poor as well as lonely or sick people, those with reduced mobility or living in unsuitable housing conditions. Natural disasters are never completely quite so because of the frequency of the disasters as well as their human, community and social consequences and the extent of the subsequent material damage. They can be regarded as the result of human factors related to the deployment of ill advised activities for the environment (hasty urbanization and industrialization, deforestation, construction in zones at risk, etc), socio-economic conflicts (wars, political conflicts, displacement of segments of the population in environments at risk) or unequal distribution of economic, social and cultural resources between individuals, communities and countries. In social work, when we examine the causes and consequences of disasters on people's health and social activities, it is important to consider the notion of individual and social vulnerability of the people as well as the concepts of human adaptation to stress and impact strength. This communication will mainly make it possible to place the consequences of natural disasters in their social context and discuss the repercussions of this concept of reality on workers training and guiding.

Prehosp Disaster Med 2011;26(Suppl. 1):s130

doi:10.1017/S1049023X11004286

(P1-97) Long-Term Effects of a Flood on the Psychosocial Health of Victims

D. Maltais, L. Lachance

Human Science, Chicoutimi, Canada
Long term Effects of a Flood on the Psychosocial Health of Victims D. Maltais ${ }^{1}$ et L. Lachance ${ }^{2}$, Université du Québec à Chicoutimi, Québec, Canada, ${ }^{1}$ Département des sciences humaines, ${ }^{2}$ Département des sciences de la santé In July 1996, floods disrupted the lives of thousands of people living in rural and urban communities in the Saguenay area of Quebec. Data collected three years after the events showed that flood victims experienced more precarious psychological health, with various factors being controlled including sex, age, and life events. Flood victims demonstrated more post-traumatic symptoms, somatic symptoms, social dysfunctions, and depressive symptoms than non-victims. Victims also showed significantly lower levels of psychological well-being than non-victims. In order to identify the long-term impacts of flood exposure, a second study was conducted eight years after the event (2004) with the same groups of victims $(N=129)$ and non-victims $(N$ $=89$ ). Variance analyses show that urban survivors obtained improved scores on scales measuring PTSD, and depression yet remained significantly more affected than non-victims. Over time, victims also obtained improved scores on the GHQ-28 and the Affect Balance Scale yet also remained significantly different from non-victims on the GHQ-28. Rural victims improved their GHQ scores over time as well, yet maintained significant differences with rural non-victims for the PTSD score. No significant differences were observed over time (time 1 and time 2) or between groups (victims and non-victims) regarding psychological well-being and depressive symptoms in rural area.

Prehosp Disaster Med 2011;26(Suppl. 1):s130 doi:10.1017/S1049023X11004298

(P1-98) Psychological Aspects of the Disaster Victim Identification (DVI)

S. Vymetal, M. Kvasnickova

Psychology Section, Prague, Czech Republic

The process of identification of disaster and mass casualties' victims (Disaster Victim Identification - DVI) impose requirements on the interdisciplinary cooperation of experts in many professions. When working with survivors and witnesses, it is necessary to maintain general ethical principles and follow the guidelines of optimal crisis communication with the affected people. The important thing is not to cause further secondary trauma. It is therefore necessary to understand the normal reactions of the human psyche in extreme stress and psychosocial needs of the people in stressful situations. Also members of DVI teams deserve adequate psychosocial support during and after the completion of difficult tasks. It is likely that these workers are psychologically resistant to extreme stress comparing to the general population but they are also increasingly exposed. To maintain work performance and life satisfaction is the possibility to use a specific psychological support very important. Keywords: acute stress reaction (ASR), DVI teams, disaster victim identification, crisis communication, survivors, crisis and disaster psychology, psychosocial crisis management, psychosocial care, posttraumatic stress disorder (PTSD).

Prehosp Disaster Med 2011;26(Suppl. 1):s130 doi:10.1017/S1049023X11004304 